\section{Verträglichkeit, metrologische von Messergebnissen}

C. Vidal ${ }^{1}$ und W.-R. Külpmann ${ }^{2}$

${ }^{1}$ Landeskriminalamt Niedersachsen, Dezernat 53 „Chemie“, Hannover, Deutschland

${ }^{2}$ Hannover, Deutschland

Englischer Begriff metrological compatibility of measurement results; metrological compatibility

Definition Eigenschaft einer Menge von Messergebnissen (s. \ Messergebnis) für eine $\triangleright$ Messgröße in der Weise, dass der Absolutwert der Differenz eines beliebigen Paares der Messwerte (s. - Messwert) aus 2 unterschiedlichen Messergebnissen kleiner ist als ein gewähltes Vielfaches der Standardmessunsicherheit dieser Differenz (Brinkmann 2012). Für Anmerkungen s. Literatur.

\section{Literatur}

Brinkmann B (2012) Internationales Wörterbuch der Metrologie (VIM) Deutsch-englische Fassung. ISO/IEC-Leitfaden 99:2007, 4. Aufl. Beuth-Verlag, Berlin 